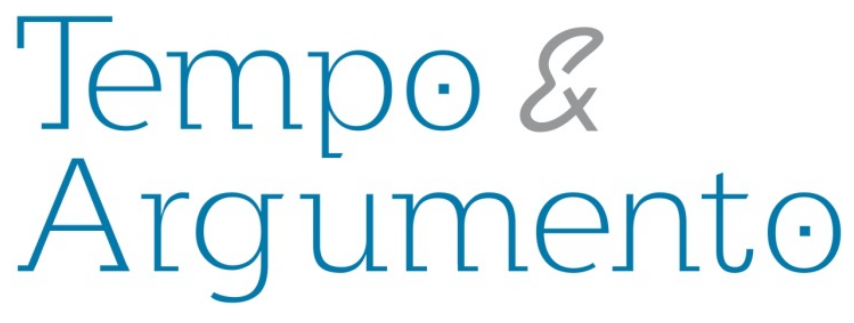

\title{
Acervo da DOPS/PR: uma possibilidade de fonte diferenciada para a história da educação
}

\begin{abstract}
Resumo
Este artigo objetiva analisar o acervo das extintas Delegacias de Ordem Política e Social (DOPS) como forma de contribuir para a eleição de novas fontes para as pesquisas em história da educação. Apresentamos a importância da utilização de fontes diferenciadas para a história da educação, como as provenientes da história legislativa, executiva e judiciária, da administração pública, da economia, do governo e dos partidos políticos. Ademais, estes materiais permitem compreender o fenômeno educativo e suas mediações sociais, políticas, culturais e históricas, internas e externas, a cada objeto pesquisado. Como o foco é a documentação da DOPS/PR, observou-se a relevância de se caracterizar este órgão estatal, que ficou mais conhecido por suas ações repressivas exercidas no regime ditatorial, mas que esteve ativo no período considerado democrático. Explicamos como esta documentação foi transferida ao Arquivo Público do Estado, e quais as dificuldades ou inconvenientes que os pesquisadores se deparam ao trabalhar com este material, entre as quais estão o extravio de parte da documentação, a destruição da organização original do arquivo e a desordem temporal e temática em alguns dossiês. Por fim, através do banco de dados de teses e dissertações da Coordenação de Aperfeiçoamento de Pessoal de Nível Superior (CAPES), mostra-se como vêm sendo desenvolvidas as pesquisas com este corpus documental.
\end{abstract}

Palavras-chave: Fontes. História da educação. DOPS/PR

\author{
Ana Karine Braggio \\ Doutoranda em Educação pela \\ Universidade Estadual de Maringá. \\ anakarinebraggio@hotmail.com
}

\section{Alexandre Felipe Fiuza}

Pós-doutor em História Contemporânea pela Universidade Autônoma de Madri/ Espanha. Coordenador do Mestrado em Educação da Universidade Estadual do Oeste do Paraná. alefiuza@terra.com.br

\section{Para citar este artigo:}

FIUZA, Alexandre Felipe; BRAGGIO, Ana Karine. Acervo da DOPS/PR: uma possibilidade de fonte diferenciada para a história da educação. Revista Tempo e Argumento, Florianópolis, v. 5, n.10, jul./dez. 2013. p. $430-452$. 


\title{
The archive of the DOPS/PR
}

[Department of Political and

Social Order of the State of

Paraná]: the possibility of a different source for the history of education

\begin{abstract}
This article aims to analyze the archive of the extinct Police of Political and Social Order ( DOPS ) as a way of offerering new sources for research on the history of education. We explain the importance of using different sources for the research on this field, such as the ones coming from the legislative, executive and judicial history, public administration, economics, government and political parties. Moreover, these materials allow us to understand the phenomenon of education and its social, political, cultural and historical mediations, internal and external to each analyzed object. Since the focus is the documentation of DOPS / PR, we noted the importance of characterizing this state agency, which is best known for its repressive actions undertaken during the dictatorship, but which was active in the period considered democratic. We explain how this documentation was transferred to the State Public Archives, and what difficulties or inconveniences the researchers encounter when working with this material, among which are the loss of part of the documentation, the destruction of the original file organization, and the temporal and thematic disorder of some of the files. Finally, through the database of theses and dissertations of the Coordenação de Aperfeiçoamento de Pessoal de Nível Superior (CAPES), we show how the researches have been developed by making use of this documental corpus.
\end{abstract}

Keywords: Sources. History of education. DOPS/PR. 


\section{Introdução}

A partir de dois fatos ocorridos na década de 1990, um extraído da leitura do texto sobre fontes de Catani e Faria Filho (2005), e outro de Bacellar, respectivamente, a confirmação da utilização de novas fontes para a história da educação e a abertura para pesquisa dos arquivos das extintas Delegacias de Ordem Política e Social (DOPS) ${ }^{1}$, objetivamos neste artigo analisar o acervo da DOPS como uma possibilidade de fonte diferenciada para a história da educação.

Como mostram Catani e Faria Filho ao analisarem as produções científicas apresentadas no grupo de trabalho de história da educação da Associação Nacional de Pós-Graduação e Pesquisa em Educação (ANPEd) entre os anos de 1985 a 2000, 59,3\% destas condizem com estudos realizados pela lente da organização escolar ou do pensamento pedagógico, ou pela união de ambas as perspectivas ${ }^{2}$. Os outros $40,7 \%$ são agregados a outros temas não especificados, mas que também se inserem na história da educação. Segundo os autores, a categoria "outros temas" é resposta da explosão de novos temas e objetos de pesquisa ocorrida nos anos de 1990, possibilitados "[...] por novos aportes teórico-metodológicos apropriados pelos pesquisadores da área" (CATANI; FARIA FILHO, 2005, p.105), confirmando que a história da educação ao longo da década de 1990 ganhou uma multiplicidade de temas e uma diversificação de fontes.

Por conseguinte, esta sustentação remete ao questionamento sobre que tipo de novas fontes ganhou espaço entre os pesquisadores de história da educação nesta década de 1990. A partir de uma categorização de Catani e Faria Filho, (2005, p.107), “[...] quase a metade das fontes utilizadas emanam diretamente de órgãos estatais [...]" sendo os documentos oficiais, legislativos, relatórios e matérias de jornais e revistas os que assumem nítido caráter oficial. Entre estas fontes oriundas dos órgãos estatais, apesar dos autores não citarem, pode-se incluir os acervos das DOPS.

\footnotetext{
${ }^{1}$ Há uma alternância do significado da sigla das chamadas DOPS até mesmo na documentação oficial, como Divisão, Delegacia ou Departamento de Ordem Política e Social (FIUZA, 2006, p. 154).

${ }^{2}$ Os temas são: sistema escolar, profissão docente, fontes e metodologia, estudos de gênero, livros e práticas de leitura, saberes escolares e, ideias pedagógicas (CATANI e FARIA FILHO, 2005, p.105).
} 
Nos anos iniciais da década de 1990 os acervos das DOPS foram transferidos para seus respectivos arquivos públicos estaduais, permitindo novas análises históricas, com fontes inéditas ${ }^{3}$. Como mostra Bacellar (2005, p.32),

Para o período republicano recente, merecem grande destaque os acervos do Deops, recolhidos aos arquivos públicos estaduais durante a década de 1990. Vastos, tais acervos vêm sendo intensamente pesquisados, revelando os bastidores da ação repressiva do Estado contra grupos ou pessoas considerados perigosos, subversivos. $O$ denso material, constituído de fichas de arquivo e de prontuários por indivíduos ou por pessoa jurídica - sindicatos e partidos, entre muitos outros - tem permitido a análise histórica sob os mais variados enfoques.

Estes documentos são denominados por Bacellar (2005, p.31) como "documentos de polícia", que "são os acervos, de maneira geral, relativos à ação repressora do Estado, em que contravenções as mais diversas são enquadradas, com indivíduos capturados, julgados e presos". No acervo da DOPS do Paraná, é possível encontrar documentos que foram selecionados e armazenados por agentes da polícia política, desde a década de 1920. Pode-se caracterizá-los em três grupos, de acordo com a natureza de produção. Existem os produzidos pela polícia política, onde se encontram documentos como relatórios, informes, ofícios expedidos e recebidos, radiogramas, telegramas, fichas de identificação criminal, pedidos de busca e apreensão, inquéritos, e fotografias. Reúnem também os produzidos pelos indivíduos ou instituições/grupos/entidades que estavam sob vigilância, e assim foram arquivados pelos agentes da DOPS. Por exemplo, do movimento estudantil, existem panfletos, manifestos, cartazes, flâmulas, estatutos de centros acadêmicos, constituição da entidade estudantil, textos de peças teatrais, relatórios dos congressos e seminários, rascunhos, correspondências, informes e revistas estudantis. E, por último, mas não menos importante, encontram-se os documentos produzidos por terceiros, como a Imprensa, onde estão os recortes de jornais e revistas.

\footnotetext{
${ }^{3}$ Em cada estado que possuía sua DOPS houve uma situação peculiar na data de repasse do acervo que estava sob a guarda de um órgão policial para seu respectivo arquivo público, já que cada processo executou-se a partir de leis de nível estadual, influenciadas pela Constituição de 1988, que, por seu turno, previa o direito de informação, conhecido como o princípio do habeas-data (tenhas a tua informação).
} 
À primeira vista, parece curioso eleger documentos policiais como fontes para as pesquisas em história da educação. Assim, é preciso frisar que para analisar a história da educação não existem fontes restritas, capazes de explicar por si só as dinâmicas internas de cada problema educacional. Compreender as relações complexas, internas e externas a cada objeto pesquisado, exige uma aproximação entre diferentes contextos. Como aponta Ragazzini (2011, p.23), "os dados de uma escola não explicam o conjunto da pedagogia geral de uma época e, muito menos, o contexto histórico geral e a legislação vigente". A história da educação se faz por um conjunto de fontes provenientes da história legislativa, executiva e judiciária, da administração pública, da economia, do governo e dos partidos políticos, e não unicamente da história da educação (RAGAZZINI, 2001, p.19).

Por exemplo, um caderno escolar da época da ditadura civil-militar brasileira, que esteve correlacionada com a formação do bom cidadão e com o fortalecimento da ordem política e social, não é capaz de explicar todo o contexto histórico geral da época, a saber: as manifestações culturais e populares a favor da democracia, a vigilância aos professores e aos movimentos estudantis, a requisição de documento de bons antecedentes, que muitos trabalhadores eram obrigados a obter para exercer sua profissão, a instauração de atos institucionais, entre outros. Por sua vez, nem mesmo o contrário é possível, pois um documento governamental é incapaz de explicar como ocorria o ensino no interior de uma classe. Assim, a história da educação não necessita ser escrita apenas por documentos que provêm diretamente da educação. Porém, as fontes não possuem o mesmo caráter utilitário. A partir de cada problemática, o pesquisador deve selecionar as fontes normativas para a pesquisa, que serão as diretamente relacionadas ao objeto e à sua problemática, e as orientadoras da pesquisa, que serão as externas ao objeto e a sua problemática, mas que são imprescindíveis para a compreensão das suas relações sociais, por conseguinte, para a compreensão do contexto histórico da época a ser analisada.

Embora prevaleça a educação formal na historiografia da educação, estas novas fontes também revelam as diferentes instâncias em que a educação informal postula um lugar na formação da população. Como se vê, o trato das fontes deve levar em 
consideração a utilização de variadas fontes, inclusive documentos policiais, que são fundamentais e inevitáveis para compreender o contexto político, econômico e social, para que assim as pesquisas em história da educação possam abranger o conjunto das relações sociais, que são criadas a partir da relação de produção, e definem a pedagogia geral $^{4}$. Após estes primeiros apontamentos, este artigo está estruturado em tópicos. $\mathrm{O}$ próximo tópico explana o que foi a DOPS/PR, e quais eram as funções exercidas por seus agentes. Posteriormente, apresenta-se o que é o acervo da DOPS/PR, como se estrutura, e quais os cuidados que se deve ter ao trabalhar com este tipo de documentação, ainda pouco conhecida por pesquisadores da educação. Por fim, aponta-se como estes tipos de documentos estão sendo abordados em algumas pesquisas, rastreadas através do banco de dados de teses e dissertações da Coordenação de Aperfeiçoamento de Pessoal de Nível Superior (CAPES).

\section{O que foi a DOPS/PR}

As DOPS foram órgãos do aparato repressivo brasileiro, criados com a função de controlar a ordem política e social, respondendo às concepções de segurança de cada época. Elas surgiram principalmente na segunda metade da década de 1930, após sugestão dada no ano de 1936 pelo congresso dos secretários de segurança e chefes de polícia, que ocorreu no distrito da Guanabara, convocado pelos chefes de polícia do Distrito Federal e pelo Ministério da Justiça. O intuito era estreitar laços entre as polícias estaduais, e uniformizar e racionalizar no país meios para defender o regime instituído na época pelo presidente Getúlio Vargas, e inibir a expansão de extremistas comunistas ${ }^{5}$. A

\footnotetext{
${ }^{4}$ Ao dizer pedagogia geral entende-se que o ato pedagógico perpassa toda a sociedade, extrapolando $o$ âmbito escolar formal. Como assevera Libâneo: "Pedagogia é, então, o campo do conhecimento que se ocupa do estudo sistemático da educação, isto é, do ato educativo, da prática educativa concreta que se realiza na sociedade como um dos ingredientes básicos da configuração da atividade humana. Nesse sentido, educação é o conjunto das ações, processos, influências, estruturas, que intervém no desenvolvimento humano de indivíduos e grupos na sua relação ativa com o meio natural e social, num determinado contexto de relações entre grupos e classes sociais. É uma prática social que atua na configuração da existência humana individual e grupal, para realizar nos sujeitos humanos as características de 'ser humano'." (destaque do original, 2007, p.30).

${ }^{5}$ Até então as DOPS que já haviam sido criadas, como por exemplo, as duas primeiras, a DOPS de São Paulo, em 1924, a e Delegacia de Segurança Pessoal e Ordem Política e Social de Minas Gerais, em 1927,
} 
DOPS no Paraná foi criada em 1937, mas conforme já comentado, entre os documentos de seu acervo encontram-se alguns datados da década de 1920. Apesar de naquele momento não existir ainda a DOPS, as atividades de investigação e controle social no Estado eram feitas pelo comissariado de investigação e segurança pública. Na década de 1930 tais atividades passaram a ser responsabilidade da Delegacia de Vigilância e Investigação, e da Delegacia de Vigilância e Capturas e, posteriormente, da DOPS (DEAP/PR, s.d.; MOTTA, 2006, p.57).

Na mesma década de criação da DOPS/PR, também surgiu a Lei de Segurança Nacional, $n^{\circ} 38$ de 4 de abril de 1935, onde se definiu o que deveria ser considerado ordem política e social. Assim, estabeleceram-se com propriedade quais as ações que seriam exercidas pelos órgãos da polícia política. De acordo com o primeiro e o segundo parágrafos do artigo 22 desta Lei, tem-se a compreensão de que ordem política "[...] é a que resulta da independência, soberania e integridade territorial da União, bem como da organização e atividade dos poderes políticos, estabelecidas na Constituição da República, nas dos Estados e nas leis orgânicas respectivas”, e que ordem social

[...] é a estabelecida pela Constituição e pelas leis relativamente aos direitos e garantias individuais e sua protecção civil e penal; ao regime jurídico da propriedade, da família e do trabalho; a organização e funccionamento dos serviços publicos e de utilidade geral; aos direitos e deveres das pessoas de direito publico para com os individuos e reciprocamente - Lei n³8/1935 (BRASIL, 1935).

Assim, competia à DOPS/PR:

[...] dentre outras atividades, a prevenção, repressão e processamento no município da Capital, não só dos delitos de ordem política e social, como também dos crimes contra a organização do trabalho, a segurança dos meios de comunicação e transporte e outros serviços públicos; a investigação, prevenção, repressão e processamento no município da Capital das infrações previstas na Lei das Contravenções Penais; providenciar na permuta com as polícias dos Estados, Distrito Federal e territórios e com quaisquer delegacias ou autoridades, as informações referentes aos indivíduos considerados perigosos à ordem política e social (DEAP/PR, s.d.). 
Como se pode notar pelo excerto acima, existia uma circulação de informações policiais sobre indivíduos considerados perigosos. Para as DOPS poderem funcionar, necessitavam de um setor de arquivo onde estivessem contidas informações, fichadas e organizadas, de todos os indivíduos processados ou suspeitos de cometer atividades causadoras de desordens, já que sua base era o gerenciamento de informações. Neste universo, a agilidade e a organização da documentação em fichas individuais ou temáticas arquivadas pela DOPS era questão imprescindível para todo o funcionamento dos trabalhos de investigação, censura e repressão.

Essas três funções - investigação, censura e repressão - seguiam praticamente um roteiro pré-estabelecido, que vale ser transcrito:

a) investigação: ocorria por meio de coleta de dados e vigilância preventiva daquele considerado suspeito, e os dados coletados poderiam ou não fazer parte de um prontuário da instituição ou indivíduo investigado; os documentos coletados eram: radiogramas, fotografias, recortes de jornais, entre outros; b) censura: caracteriza-se no procedimento adotado após a investigação ou paralela a ela; quando averiguada a existência de alguma atividade que representasse subversão, era então feito controle político-cultural a qualquer forma de expressão que significasse ameaça à ordem estabelecida; c) repressão: digamos que essa seria a última instância de atuação da polícia política, e que ocorria após constatado que havia atividade subversiva, sendo que as ações poderiam ser a princípio através de perseguição política até a ações de castigos físicos, caracterizados como tortura (SCHMITT, 2011, p.87-8).

Quando a atividade de alguma pessoa física ou jurídica - principalmente relacionada com alguma entidade alvo de investigação - era suspeita, o primeiro passo consistia em averiguar, pesquisar e diagnosticar o suposto delito, através de

[...] acompanhamento sistemático, coleta de dados e vigilância preventiva do objeto da investigação, gerando uma documentação característica, com pedido de busca, sindicância, parte de serviço, radiogramas, fotografias, recortes de jornais, telegramas, que passariam a fazer parte ou não do prontuário funcional ou individual da entidade ou indivíduo [...] (PÁDUA; GAMA, 1998, p.29). 
Com este acompanhamento, toda atividade sob investigação tinha suas informações organizadas em prontuários funcionais, fundamentalmente com objetivo preventivo. Sendo diagnosticado o risco eminente da atividade investigada, o segundo passo que ocorria após a investigação, ou concomitante a ela, consistia em controlar a ameaça à ordem social estabelecida pelo poder instituído. Qualquer ideia ou pensamento que fosse considerado capaz de expressar uma forma subversiva era tido como ameaça, portanto passível de estar sob vigilância, e acompanhada pelo serviço de censura. Houve então algumas pessoas e entidades permanentemente sob vigilância, "[...] seja porque agregam um número significativo de indivíduos (fábricas, igrejas), seja porque atuam como formadores de opinião (imprensa), ou porque adotam postura contrária ao sistema, atentando ainda contra a 'moral e bons costumes'." (PÁDUA; GAMA, 1998, p.30).

Quando a documentação angariada pelo processo de investigação e censura comprovava se tratar de atividades subversivas, passava a ser utilizada para compor o dossiê de provas incriminatórias, juntamente com fichas de identificação criminal, antecedentes criminais do indivíduo, pronunciamentos, pedidos de busca e apreensão, recortes de jornais, relatórios, entre outros. Com a comprovação da subversão, a esfera subjetiva da repressão era acionada. Ou seja, buscava-se lidar com as ideias dos reprimidos, cassando, por exemplo, suas licenças de funcionamento para os estabelecimentos, deportando os estrangeiros, destruindo bens individuais, e amedrontando através de perseguições. Principalmente durante a ditadura civil-militar, instaurada em 1964, os castigos repressivos se elevaram, chegando à repressão física, caracterizadas por atos de tortura (PÁDUA; GAMA, 1998, p.31-2).

Ao final da ditadura civil-militar as DOPS foram extintas, ou seja, entre os anos de 1983 e 1984. Porém, o controle das informações arquivadas não foi publicizado e esclarecido neste período. Assim, há fortes indícios de que, por cerca de mais uma década, as Secretarias de Segurança Pública tenham continuado com seu trabalho de vigilância política. Como aponta Fiuza (2006, p.24), as vigilâncias realizadas pela Delegacia não se encerraram com o fim da ditadura civil-militar, e ainda hoje podem estar sendo desempenhadas pela chamada polícia reservada. No caso da documentação da DOPS/PR, 
somente no dia 11 de julho de 1991, com a aprovação do Decreto $n^{\circ} 577$, a Subdivisão de Informações da Polícia Civil, que estava com a documentação da polícia política, foi extinta e teve seu acervo arquivístico transferido para o departamento estadual de arquivo público.

\section{O acervo DOPS/PR}

De acordo com os assessores técnicos do departamento estadual de arquivo público do Paraná, Roncaglio, Szvarça e Bojanoski, tendo por base um ofício datado de 03 de julho de 1991 (oito dias antes da publicação do Decreto $n^{\circ} 577$ ), relatam que alguns funcionários do Departamento de Arquivo Público foram solicitados pela Subdivisão de Informações da Polícia Civil a tomar conhecimento do estado do acervo arquivístico, com o objetivo de avaliar as condições necessárias para posteriormente guardá-lo. Tais funcionários tiveram o contato com "[...] uma sala de aproximadamente $60 \mathrm{~m}^{2}$,onde estavam localizados trinta arquivos de aço [...]" (RONCAGLIO; SZVARÇA; BOJANOSKI, 1998, p.41). Porém, destes trinta arquivos, vinte e três foram transferidos para a estrutura do arquivo público, onde ficaram conhecidos pela denominação de acervo da DOPS; os outros sete ficaram sob domínio da polícia após realizar uma triagem e alegar conter documentos de interesse para o combate à criminalidade (RONCAGLIO; SZVARÇA; BOJANOSKI, 1998, p.42).

Esta ocasião de seleção de documentos do acervo comprova a teoria de vários autores que alertam para a possibilidade de extravio de parte da documentação. Segundo Catela (2002, p.201), pesquisadora argentina, que disserta sobre os arquivos da repressão de seu país, processo homólogo aos arquivos brasileiros, visto que as finalidades de ambos eram as mesmas, “[...] la división o la separación de fondos documentales desplazados hacia otros espacios físicos indica también un cambio en el interés por su contenido [...]”.

Assim, certamente este tipo de documentação está eivado de parcialidade, e voltado diretamente à construção e invenção do inimigo político do Estado, devendo ser 
frequentemente colocado em suspeição, mas em momento algum deve ser desconsiderado. As informações deste tipo de acervo, apesar de terem sido produzidas pela polícia política, devem ser levadas em consideração, já que esta as selecionava, arquivava e classificava como subversivas.. Desconsiderá-las seria negar a primazia da contradição existente nas relações sociais. Como aponta Bacellar, faz parte da pesquisa conhecer o funcionamento da máquina administrativa e da organização do acervo para poder desvendar boa parte das contradições e confusões que fazem parte da pesquisa. Como ele afirma,

O entendimento desse grande mecanismo administrativo é fundamental para se compreender que tipos de documentos teriam sido hipoteticamente produzidos e arquivados nos desvãos das estantes dos funcionários régios. Hipoteticamente, pois nem sempre se tem plenas garantias de que tais documentos foram de fato produzidos, ou seja, se os administradores cumpriram fielmente suas obrigações. O problema é, contudo, ainda mais complexo. A elaboração de um documento não necessariamente significa que seguiram as normas de conteúdo informacional originalmente previstas. Por fim, o que foi produzido e acumulado muitas vezes se perdeu com o tempo ou com a incúria (BACELLAR, 2005, p.44).

O procedimento do pesquisador para com estas fontes deve estar longe de apenas reportar-se às informações nelas contidas, e ter a ilusão de que elas são fidedignas aos fatos tais como aconteceram. O procedimento para com elas deve ser de desmistificação e de questionamento do seu caráter. Como aponta Nunes (2005, p.73), é preciso

[...] compreender que, se a fonte tem uma referência precisa, seja pela origem, pela autoria ou pela finalidade, múltiplos podem ser os seus níveis explicativos, tanto no aspecto explícito quanto no que diz respeito às significações implícitas que o historiador vai procurar desvendar

Destas significações implícitas, os documentos da DOPS/PR estão carregados. Inclusive a ausência de documentos, que pode ser observada em determinados períodos, também é um indicativo de como se procedia às ações de vigilância da polícia política. Por que existem meses sem qualquer tipo de relatório ou informação? Onde estão atualmente os documentos "extraviados"? Quais são as informações contidas nestes 
documentos? É possível numerar três inconvenientes com os quais os pesquisadores do acervo da DOPS/PR se deparam. O primeiro, como já comentado, é que o material não foi transferido na íntegra, pois a polícia ficou com parte do acervo. O segundo é a destruição da organização original do arquivo, que quando em posse do Departamento de Arquivo Público, ganhou uma nova organização arquivística, tornando difícil, senão impossível, compreender como era feito o armazenamento das informações pela própria polícia. E o terceiro é a desorganização temporal e temática em que se encontram os documentos nos dossiês, tendo documentos fora de ordem e em pastas trocadas, o que já era alertado por Schmitt (2011, p.90). Estas questões fazem com que certos documentos, talvez imprescindíveis para o trabalho, passem despercebidos. Mas nem por isso a pesquisa estará condicionada a ser interditada; essas são dificuldades que devem fazer parte da rotina dos pesquisadores sobre a história do passado recente.

No caso do acervo do Paraná, a vantagem é que a legislação estadual permite a consulta livre aos documentos arquivados. Já em outros estados a situação é diferenciada, como aponta Fiuza (2006, p.22):

[...] a legislação de acesso à documentação varia de acordo com cada Lei estadual. Logo, enquanto em São Paulo, Paraná e Paraíba o acesso aos prontuários é livre aos pesquisadores, no Rio Grande do Sul, Rio de Janeiro e Pernambuco, estes mesmos prontuários só podem ser consultados mediante a autorização dos envolvidos ou de seus familiares mais próximos, em caso de morte dos fichados.

No Paraná, apesar das informações serem de livre acesso, a consulta aos documentos só é feita após serem tomados os devidos cuidados para a conservação dos mesmos. O acesso aos documentos originais requer um cuidado de manuseio para preservação de sua integridade, sendo necessário o uso de luvas e papéis especiais de pH alcalino, quando necessário, para realizar marcação de páginas. Como comenta Bacellar, todo cuidado é pouco, e trabalhar com arquivos exige precauções, não só para a conservação do material, mas também para a saúde do pesquisador. Houve épocas em que para se manter o arquivo protegido de traças, cupins e brocas eram usados produtos químicos tóxicos, como inseticidas (BACELLAR, 2005, p.54). Como aponta Fiuza (2006, 
p.23), a desatenção e desinformação existente em alguns arquivos estaduais, tais como em Pernambuco e na Paraíba, até meados da década passada, era preocupante, pois não conservavam os documentos devidamente. Até mesmo permitiam naquela altura, no caso paraibano, a retirada destes do prédio do acervo para serem copiados, sem existência de qualquer conferência e acompanhamento dos funcionários. Com a intervenção de pesquisadores da Universidade Federal da Paraíba (UFPB), esta prática foi extinta mediante a organização, conservação e tratamento destes documentos por profissionais especializados.

A falta de um cuidado com esta documentação não se restringe aos acervos das DOPS, mas se estende a outros documentos de grande valor para a preservação da memória do país. São inúmeros os casos de documentos abandonados em salas úmidas, não acondicionados corretamente em caixas, higienizados, classificados e digitalizados. Esta negligência pode ser explicada em parte pela incompetência dos setores que se ocupam da guarda destes acervos, pela falta de recursos para uma estrutura adequada, mas também pela opção deliberada de se deteriorar esta documentação, seja por um motivo de ordem política, seja pela ausência de uma consciência histórica.

Por outro lado, as pesquisas junto ao acervo das DOPS e aos arquivos públicos estaduais demonstram igualmente a existência de pesquisadores e funcionários capacitados e preocupados com alguns destes acervos. Sem esta intervenção deles, as valiosas fontes existentes nestes espaços estariam perdidas para sempre, o que já ocorreu com algumas documentações, objetos e outros vestígios do passado.

Valorizar estes documentos da DOPS/PR é igualmente aquilatar as produções humanas, que apesar de produzidas sem a intencionalidade de registrar sua vida e seu mundo, agora, a partir do interesse e das questões dos pesquisadores, adquirem efetivamente o caráter de fonte. Como diz Saviani (2004, p.7), esses materiais

São documentos, vestígios, indícios que foram acumulando-se ou foram sendo guardados, aos quais recorremos quando buscamos compreender determinado fenômeno. A rigor poderíamos, pois, dizer que a multidão de papéis que se acumulam nas bibliotecas e nos arquivos públicos ou privados, as miríades de peças guardadas nos museus e todos os múltiplos objetos categorizados como novas fontes pela corrente da 
"nova história" não são, em si mesmos, fontes. Com efeito, os mencionados objetos só adquirem o estatuto de fonte diante do historiador que, ao formular o seu problema de pesquisa, delimitará aqueles elementos a partir dos quais serão buscadas as respostas às questões levantadas. Em consequência, aqueles objetos em que real ou potencialmente estariam inscritas as respostas buscadas erigir-se-ão em fontes a partir das quais o conhecimento histórico referido poderá ser produzido.

São esses materiais, selecionados em consonância às perguntas dos pesquisadores, que possibilitam a compreensão das relações sociais, históricas, políticas e culturais desenvolvidas em determinado contexto, que influenciam e interferem na história da educação.

\section{Possibilidades de utilização do acervo da DOPS/PR para a história da educação: considerações finais}

Como apontou Saviani no excerto anterior, os questionamentos e objetivos delimitados nas pesquisas conduzem à utilização de determinados materiais que, no trato dos pesquisadores, ganham o caráter de fontes. Assim também ocorreu com os acervos das DOPS. A liberação para consulta na década de 1990 induziu a efetivação destes materiais a adquirir o estatuto de fontes, sendo cada vez mais utilizados em pesquisas, principalmente da área da história. Entre as teses e dissertações disponíveis no banco online da CAPES, do total de 97 pesquisas que utilizaram documentos da ou sobre as DOPS, somente quatro são produtos de programas de pós-graduação em educação, como se pode verificar nos dados da tabela a seguir ${ }^{6}$.

\footnotetext{
${ }^{6}$ A dissertação de mestrado de um dos autores deste artigo, Ana Karine Braggio, defendida em fevereiro de 2013, na Universidade Estadual do Oeste do Paraná (UNIOESTE), campus Cascavel, intitulada $O$ movimento estudantil paranaense e a vigilância política no pré-golpe civil-militar, também é produto de um programa de pós-graduação em educação, porém não está inclusa nesta produção examinada, visto que até o momento não está disponível no banco on-line de teses e dissertações da CAPES. Assim, é provável que outras pesquisas concluídas no final do ano de 2012 e início de 2013 também não estejam aqui contabilizadas. Igualmente, a tese de Doutorado em História do segundo autor, Alexandre Fiuza, intitulada Entre um samba e um fado: a censura e a repressão aos músicos no Brasil e em Portugal nas décadas de 1960 e 1970, também se ocupou da análise da documentação dos arquivos das DOPS de vários estados brasileiros, comparando com material similar do caso português, no caso da PIDE (Polícia Internacional de Defesa do Estado) e da DGS (Direcção-Geral de Segurança). Contudo, seu foco não é a
} 
Tabela - descrição quantitativa de pesquisas disponíveis no banco de teses e dissertações da CAPES, relacionadas às DOPS, Brasil, dados coletados em julho de 2013.

\begin{tabular}{|l|r|r|r|r|r|}
\hline \multirow{2}{*}{$\begin{array}{l}\text { Pesquisas dos } \\
\text { anos de } 1993 \text { a } \\
2012\end{array}$} & Quantidade & História & Educação & Outras** & $\begin{array}{c}\text { Conteúdo } \\
\text { diretamente } \\
\text { relacionado à } \\
\text { história da } \\
\text { educação }\end{array}$ \\
\cline { 3 - 5 } & $97(100 \%)$ & $64(100 \%)$ & $4(100 \%)$ & $29(100 \%)$ & $10(100 \%)$ \\
\hline $\begin{array}{l}\text { DOPS ou } \\
\text { DEOPS* }\end{array}$ & $13(13,4 \%)$ & $11(17,18 \%)$ & $2(50 \%)$ & $0(0 \%)$ & $4(40 \%)$ \\
\hline DOPS/PR & & & & & \\
\hline
\end{tabular}

Fonte: dados obtidos através de pesquisa ao banco on-line de teses e dissertações da CAPES, 2013.

\section{Notas:}

* Referente a pesquisas relacionadas às DOPS estaduais de modo geral (São Paulo, Pernambuco, Rio de Janeiro, Minas Gerais, Rio Grande do Sul, Paraná, Santa Catarina, etc.). Pesquisadores do arquivo de São Paulo costumam utilizar a nomenclatura DEOPS.

** Referente a Programas de Pós-graduação em Letras, Literatura, Ciências Sociais, Sociologia, Ciências da Computação, etc.

A hipótese da baixa utilização destes documentos nesta área é o desconhecimento dos pesquisadores da possibilidade de se trabalhar com arquivos da polícia política para abranger questões relativas à educação.

Algumas pesquisas, mesmo sem tratar especificamente da educação, conseguem visualizar a vigilância, a repressão e a censura como instrumentos de manutenção da ordem, como reforço do imaginário social, bem como garantia da hegemonia social burguesa, o que de certo modo também é um meio de educar a sociedade. Pois, como diz Libâneo, o ato pedagógico não se restringe ao trabalho desenvolvido por docentes. Pedagógico é todo ato educativo de caráter intencional, ou seja, que visa um determinado fim. A ação pedagógica é

[...] uma prática, ou seja, um conjunto de comportamentos e ações conscientes e voluntárias de transmissão de saberes (...) por explicações

temática educacional, embora as relações entre a censura e a educação informal sejam tênues. 
que apelam à razão de uma ou mais pessoas, com finalidade de: 1) modificar os comportamentos, os afetos, as representações dos ensinados... (aptidão para a mudança); 2) fazer adquirir métodos e regras fixas que permitam fazer face a situações conhecidas que se reproduzem com regularidade (aptidão para a resolução de problemas dados); fazer agir (BEILLEROT, 1985 apud LIBÂNEO, 2007, p.32-3).

Assim, as ações intencionais dos agentes da polícia política podem ser consideradas ações pedagógicas, mascaradas pela justificativa da defesa dos interesses coletivos, com o objetivo de manter sob controle a ordem política e social, e resguardar a segurança nacional para atingir o almejado desenvolvimento econômico.

Através das pesquisas com conteúdo diretamente relacionado à história da educação, é possível perceber que os arquivos das DOPS permitem abranger estudos sobre variadas questões. Destas, uma quantidade considerável foi produzida com materiais do acervo da DOPS/PR, como se vê pelos dados da tabela anterior. A primeira, do ano de 1993, foi produzida por Mario Lopes Amorim, no curso de mestrado em história da Universidade Federal do Paraná (UFPR), e está diretamente relacionada à educação. Interessante destacar que esta é a primeira, e a mais antiga das pesquisas a utilizar os arquivos da DOPS não só a nível estadual, mas também nacional. Intitulada Oficina Liberdade e Cooperação (1973-1986), a dissertação analisa a proposta alternativa da préescola Oficina, que sofreu atos de repressão por estar totalmente desvinculada da concepção oficial de educação posta pelo regime militar. Apesar de não ter sido produzida em um Programa de Pós-Graduação em Educação, esta é de grande relevância para comprovar que a linha de história da educação na década de 1990 ganhou uma diversificação de fontes e de temas, como comentaram Catani e Faria Filho (2005, p.105).

A segunda é uma tese de doutorado em Educação, do ano de 2009, produzida por Valquiria Elita Renk, também da UFPR, intitulada Aprendi falar português na escola! $O$ processo de nacionalização das escolas étnicas polonesas e ucranianas no Paraná. Ela analisa como, durante as décadas de 1920 e 1930, foi implantada a nacionalização brasileira através da legislação, fiscalização e homogeneização dos saberes através dos livros didáticos nas escolas étnicas, e como estas fizeram para manter sua identidade sem 
desconsiderar as exigências legais. Para tanto, entre as fontes de pesquisa estão os arquivos da DOPS/PR, como os dossiês de instituições e indivíduos.

A terceira pesquisa foi produzida por Silvana Lazarotto Schmitt, no ano de 2011. É a dissertação intitulada Encontros e desencontros do movimento estudantil secundarista paranaense (1964-1985), defendida junto ao Mestrado em Educação da Universidade Estadual do Oeste do Paraná (UNIOESTE), campus de Cascavel. Através dos arquivos da DOPS/PR e de entrevistas com ex-militantes do movimento estudantil, a autora mostra as características da organização do movimento paranaense, mais especificamente, examina como os estudantes secundaristas se articularam para defender seus interesses, como reagiram às políticas educacionais emanadas do governo, e como se envolveram nas lutas políticas, sociais e culturais no período da ditadura civil-militar. Interessante destacar que após desenvolver as análises documentais, ela afirma que o movimento estudantil não esteve posicionado somente no campo da esquerda, também existindo períodos e posições onde o movimento estudantil defendeu os interesses do pensamento de direita e da preservação do status quo (SCHMITT, 2011, p.13).

A quarta pesquisa também é do ano de 2011, da UNIOESTE, campus Marechal Cândido Rondon, e aborda o movimento estudantil paranaense, porém a nível universitário. A dissertação intitulada A DOPS e a repressão ao movimento estudantil em Curitiba - Paraná (1964-1969) foi produzida por Andréia Zaparte, durante seu mestrado no Programa de Pós-Graduação em História. Ela analisa o acervo da DOPS/PR focando a vigilância da polícia política ao movimento estudantil paranaense no período ditatorial.

Estas quatro pesquisas citadas, reiteramos, são as que possuem conteúdo diretamente relacionado à história da educação, e que utilizaram documentos da DOPS/PR. Duas produzidas em Programa de Pós-Graduação em Educação, e duas em Programa de Pós-Graduação em História. Porém, ainda há outras seis pesquisas que possuem conteúdo diretamente relacionado à história da educação, produzidas a partir 
de documentos de outras DOPS ou DEOPS, ou seja, de outros estados. Assim, totalizamse dez pesquisas em âmbito nacional, como mostra a tabela anterior?

Para fins de conhecimento é conveniente citar essas seis pesquisas. Em ordem cronológica, a primeira foi produzida em um Programa de Pós-Graduação em História, no ano de 2001, e trata do ensino superior durante o regime militar ${ }^{8}$. A segunda pesquisa é do ano de 2006, intitulada Escola judaica: integração social e preservação cultural (19371972). Foi produzida pela pesquisadora Edith Gross Hojda, durante seu doutorado em Língua Hebraica, Literatura e Cultura Judaica da Universidade de São Paulo (USP), onde analisa o funcionamento da Escola Israelita Brasileira Luiz Fleitlich, que durante o governo de Getúlio Vargas sofreu pressões políticas e ideológicas do DEOPS/SP, assim como várias outras comunidades estrangeiras.

A terceira pesquisa é a dissertação de Licia Maciel Hauer, produzida no ano de 2007, no Programa de Pós-Graduação em Educação da Universidade Federal Fluminense (UFF), intitulada Colégio Pedro Il no Período da Ditadura Militar: subordinação e Resistência. Ela mostra como as ações repressivas e controladoras dos anos da ditadura civil-militar influenciaram as concepções administrativas e pedagógicas do Colégio Pedro II. Utiliza-se dos arquivos da secretaria de ensino para averiguar os processos de resistência e subordinação no interior do mesmo, os documentos do DOPS/RJ para compreender questões políticas, e jornais com informações sobre os grêmios estudantis.

A quarta é a dissertação Em câmara lenta, de Renato Tapajós: a história do livro, experiência histórica da repressão e narrativa literária, do Programa de Pós-Graduação em História Social, da USP, do ano de 2008, onde Eloisa Aragão Maués demonstra como a experiência da luta armada do militante Renato Tapajós, integrante do agrupamento

\footnotetext{
${ }^{7}$ Lembramos que provavelmente o número de pesquisas é maior, pois não estão contabilizadas as pesquisas concluídas no final do ano de 2012 e início de 2013, por ainda não estarem disponíveis no banco on-line de teses e dissertações da CAPES, como por exemplo, a dissertação de mestrado de um dos autores deste artigo, citada na nota de rodapé anterior.

${ }^{8}$ Estas são as únicas informações que temos para disponibilizar, pois ao buscar novamente mais informações sobre a mesma, deparamo-nos com uma nova versão do banco on-line de teses e dissertações da CAPES, que após o dia 14 de outubro de 2013 está disponibilizando apenas as pesquisas produzidas entre os anos de 2005 e 2012.
} 
urbano Ala Vermelha, se transformou no livro Em câmara lenta, escrito por ele e publicado em 1977. Através do estudo da história do livro, e com base nos documentos do DEOPS/SP, produzidos durante a investigação do mesmo, ela descreve os procedimentos empregados pela polícia política para a formação da culpa dirigida contra o autor.

A quinta pesquisa é do ano de 2010. Foi produzida na Universidade Federal do Rio de Janeiro (UFRJ), no doutorado do Programa de Pós-Graduação em Antropologia Social, pela pesquisadora Luciana Lombardo Costa Pereira, sob o título A Lista Negra dos Livros Apreendidos pela Polícia Política no Rio de Janeiro. Ela mostra a repressão policial como um meio utilizado para a manutenção e organização da cultura hegemônica, ao analisar os livros apreendidos pelo DOPS/RJ, e a documentação produzida por essa polícia, que visava combater o comunismo em nome da Ideologia da Segurança Nacional.

A sexta e última pesquisa é do ano de 2011, intitulada O Colégio Canadá nos arquivos do DEOPS/SP, produzida por José Esteves Evagelidis, durante seu mestrado em Educação na Universidade Católica de Santos (UniSantos). Ele analisou nos arquivos da DEOPS/SP todas as informações sobre o Colégio Canadá, o maior colégio do Estado, arquivadas pela polícia política durante o período ditatorial. Deste modo, também analisou o grêmio estudantil existente no mesmo.

Assim, não só pelas pesquisas produzidas com arquivos do acervo da DOPS/PR, pode-se observar que há uma grande possibilidade de estudos e análises que podem ser desenvolvidos com documentos policiais, como os denominou Bacellar. As pesquisas podem abranger a história e a trajetória de instituições educativas, desde as pré-escolares até as de ensino superior. Os períodos temporais podem ser longos ou curtos, de acordo com o objetivo dos pesquisadores, pois há materiais de desde a década de 1920. A ênfase pode ser dada aos modelos de ensino, ao conteúdo programático, às ações paralelas, como teatro na escola, ou à análise da estrutura escolar em seus aspectos administrativos, no corpo docente e corpo discente, bem como aos movimentos estudantis e sindicatos dos professores. É possível estudar as interferências e influências de alguns governos nas ações pedagógicas internas da instituição, como eram recepcionadas nas escolas e nas universidades as políticas, ideologias e legislações 
emanadas do Estado. Igualmente, podem-se conhecer quais os livros e conteúdos que foram censurados, principalmente durante os governos ditatoriais.

Observa-se uma frágil consciência da importância da preservação destes documentos, e não apenas por parte do Estado e de seus agentes, pois uma significativa parcela dos próprios movimentos organizados da sociedade civil não resguardou sua própria documentação. Em parte, isso se explica pelo contexto autoritário pelo qual passou o país e alguns estados, mesmo no chamado período democrático. Afinal, salvaguardar alguns destes documentos era possibilitar a produção das provas incriminatórias pelas estruturas repressivas. Inicialmente criadas com um fim persecutório, pernicioso, repressivo e representativo dos interesses das elites dominantes nacionais e regionais, esta documentação das DOPS também pode revelar fontes importantes para a reconstrução do passado recente do país, bem como reavivar a relevância do conhecimento do passado para a solidificação de uma sociedade que não reproduza soluções de cunho autoritário. Por outro lado, não se pode desconsiderar sua importância para a culpabilização daqueles que não apenas registraram informações técnicas e corriqueiras, mas que levaram centenas de pessoas à prisão, morte, tortura e ao desaparecimento.

\section{Referências}

AMORIM, Mario Lopes. Oficina - liberdade e cooperação (1973-1986). Dissertação (Mestrado) - Universidade Federal do Paraná, Mestrado em História do Brasil, Curitiba, 1993.

BACELLAR, Carlos. Fontes documentais: uso e mau uso dos arquivos. In: PINSKY, Carla. (Org.). Fontes históricas. São Paulo: Contexto, 2005, p.23-79.

BRASIL. Lei 38, de 4 de abril de 1935. Define crimes contra a ordem política e social. Disponível em: <http://www2.camara.gov.br/legin/fed/lei/1930-1939/lei-38-4-abril-1935397878-republicacao-77367-pl.html>. Acesso em: 20 jul. 2013. 
CATANI, Denise Bárbara; FARIA FILHO, Luciano Mendes de. Um lugar de produção e a produção de um lugar: história e historiografia da educação brasileira nos anos de 1980 e de 1990 - a produção divulgada no GT História da Educação. In: GONDRA, José Gonçalves (org.). Pesquisa em história da educação no Brasil. Rio de Janeiro: D\&A, 2005.

CATELA, Ludmila da Silva. El Mundo de Los archivos. In: CATELA, Ludmila da Silva; JELIN, Elizabeth. (Comps.) Los arquivos de la represión: documentos, memoria y verdad. Madrid: siglo veintiune de españa editores. Set. 2002.

DEAP/PR; Departamento estadual de arquivo público do Paraná. Memórias Reveladas: Delegacia de Ordem Política e Social do Paraná, [s.d.]. Disponível em:

<http://www.an.gov.br/mr/Multinivel/Ver_Consulta_Fundo_Reduzida.asp?v_FlagBack=2\& v_CodReferencia_ID=554\&v_codFundo_ID=>. Acesso em: 27 nov. 2013.

EVAGELIDIS, José Esteves. O Colégio Canadá nos arquivos do DEOPS/SP. Dissertação (Mestrado) - Universidade Católica de Santos, Mestrado em Educação, Santos, 2011.

FIUZA, Alexandre Felipe. Entre um samba e um fado: a censura e a repressão aos músicos no Brasil e em Portugal nas décadas de 1960 e 1970. Tese (doutorado) - Universidade Estadual Paulista, Doutorado em História, Assis, 2006.

HAUER, Licia Maciel. Colégio Pedro Il no período da ditadura militar: subordinação e resistência. Dissertação (mestrado) - Universidade Federal Fluminense, Mestrado em Educação, Niterói, 2007.

HOJDA, Edith Gross. Escola judaica: integração social e preservação cultural (1937-1972). Tese (doutorado) - Universidade de São Paulo, Doutorado em Língua Hebraica, Literatura e Cultura Judaica, São Paulo, 2006.

LIBÂNEO, José Carlos. O campo do conhecimento pedagógico e a identidade profissional do pedagogo. In: LIBÂNEO, José Carlos (org.). Pedagogia e pedagogos, para quê? $9^{\text {a }}$ edição. São Paulo: Cortez, 2007.

MAUÉS, Eloisa Aragão. Em câmara lenta, de Renato Tapajós: a história do livro, experiência histórica da repressão e narrativa literária. Dissertação (mestrado) - Universidade de São Paulo, Mestrado em História Social, São Paulo, 2008.

MOTTA, Rodrigo Patto Sá. Ofício das Sombras. Revista do Arquivo Público Mineiro. v.XLII, n.1, p.52-67, 2006. 
NUNES, Clarice. Interrogando a avaliação dos trabalhos de história da educação: o inventário de uma prática. In: GONDRA, José Gonçalves (Org.); VIEIRA, Carlos Eduardo; et. al.. Pesquisa em história da educação no Brasil. Rio de Janeiro: DP\&A, 2005.

PÁDUA, Mônica; GAMA, Marcília. DOPS - do recolhimento ao acesso: o caso de Pernambuco. Quadrilátero: revista do arquivo público do Distrito Federal. Brasília, v.1, p.2740, mar./ago. 1998.

PARANÁ. Lei 577, de 11 de julho de 1991. Transfere para o Departamento de Arquivo Público o acervo arquivístico da Subdivisão de Informações da Polícia Civil. Disponível em: <http://200.189.113.39/sesp/legsesp.nsf/abdc1a1c48eed83a83256d7c0064aac9/245bc7fd32 19bedo032569890074236b?OpenDocument>. Acesso em: 20 jul. 2013.

PEREIRA, Luciana Lombardo Costa. A Lista negra dos livros apreendidos pela Polícia Política no Rio de Janeiro. Tese (doutorado) - Universidade Federal do Rio de Janeiro, Doutorado em Antropologia, Rio de Janeiro, 2010.

RAGAZZINI, Dario. Para quem e o que testemunham as fontes da história da educação? Educar em Revista, Curitiba, n.18, p.13-28, 2011.

RENK, Valquiria Elita. Aprendi falar português na escola! O processo de nacionalização das escolas étnicas polonesas e ucranianas no Paraná. Tese (doutorado) - Universidade Federal do Paraná, Doutorado em Educação, Curitiba, 2009.

RONCAGLIO, Cynthia; SZVARÇA, Décio Roberto; BOJANOSKI, Silvana de Fátima. Os arquivos da DOPS do Paraná. Quadrilátero: Revista do Arquivo Público do Distrito Federal. Brasília, v.1, p.27-40, mar./ago. 1998.

SAVIANI, Dermeval. Breves considerações sobre fontes para a história da educação. In: LOMBARDI, José Claudinei; NASCIMENTO, Maria Isabel Moura (Orgs.). Fontes, história e historiografia da educação. Campinas: Autores Associados; HISTEDBR; Curitiba: PUC-PR; Palmas: UNICS; Ponta Grossa: UEPG, 2004.

SCHMITT, Silvana Lazzarotto. Encontros e desencontros do movimento estudantil Secundarista Paranaense. (1964-1985). Dissertação (mestrado) - Universidade Estadual do Oeste do Paraná, Mestrado em Educação, Cascavel, 2011.

ZAPARTE, Andreia. A DOPS e a repressão ao movimento estudantil em Curitiba - Paraná (1964-1969). Dissertação (mestrado) - Universidade Estadual do Oeste do Paraná, Mestrado em História, Marechal Cândido Rondon, 2011. 
Recebido em: 30/08/2013 Aprovado em: 04/11/2013

Universidade do Estado de Santa Catarina - UDESC Programa de Pós-Graduação em História - PPGH Revista Tempo e Argumento Volume 05 - Número 10 - Ano 2013 tempoeargumento@gmail.com 